\title{
EDITORIAL
}

\section{Is COVID Era the Beginning of a Paradigm Shift in Anatomy Education?}

\section{TARANIKANTI V}

The COVID-19 pandemic has affected every person and every sphere of life globally. It has overwhelmed the medical facilities across the globe and as of date has infected more than 40 million people and claimed over 1 million lives (Johns Hopkins University and Medicine 2020). It has not only affected the routine patient-care but also educational and research activities worldwide. It has ushered in significant changes in medical education, most notably in terms of content delivery and provision of assessments; facilitated the introduction of many new educational methods in medical schools each of which with potential merits and drawbacks.

Gross anatomy during preclinical years forms one of the strong pillars of medical education. It initiates students into learning the secrets of human body through dissection. Human cadaveric dissection has been used as the core teaching tool in anatomy for centuries and many medical schools still depend on student dissection as an essential part of medical student training To date, except for Australia where cadaveric dissection is made optional, other continents like Africa, Asia, the Americas, and Europe still rely one way or another on the usage of cadavers for teaching and research (Onigbinde et al. 2020). One of the main concerns has been the vulnerability to coronavirus infection through the continuous use of cadavers for teaching. World Health Organization (WHO) disclosed that there are no reports of contracting COVID-19 infection from corona virus afflicted cadavers, though the virus can potentially remain viable on surfaces for about 9 days (WHO 2020). As a result, access to donor-based dissection in labs has become limited or nonexistent.

During this crisis, information technology has come to the aid of anatomists. Videos from Grant's dissector, Gray's photographic images, online software for virtual and augmented realityarebeing increasingly used to impart anatomy teaching. Zoom, Google meet, Microsoft teams and other online platforms are used to deliver synchronous and asynchronous interactive sessions both in large groups and small groups virtually. Many schools in the developed countries and developing countries have instantly adopted to these hightech alternatives as they have already

Address for correspondence and reprint requests: Varna Taranikanti. Department of Foundational Medical Studies, OUWB School of Medicine, Rochester, MI 48309-4401. Tel: +(248) 370-3886 E-mail: taranikanti@oakland.edu 
been using these tools in teaching anatomy as an adjunct to dissection. Students have been able to visualise the human body using the highly advanced 3-D anatomy software tools (VR headsets or augmented-reality goggles) which provide a realistic view of living organs. These tools also help in building the 3-D mind's eye to look at different body parts from all angles which simulates a living human body in understanding the depth and relations and can be used back and forth. Simultaneously they can connect structure with function by watching the muscles action on joints or understanding the movement of the vocal cords and the muscles acting on it. Above all, students could learn at their own pace as they are clean and can easily be navigated.

Post COVID-19, the biggest debatable dilemma among medical educationists and anatomists will be the changes that need to be incorporated in anatomy education. COVID-19 has taught us that technology can replace majority of the gross anatomy learning experience! There are also economic implications about going 'cadaver less'. Setting up an anatomy laboratory, space and above all the safety measures for maintenance of donor bodies requires millions of dollars.

However, 'the practice of medicine is an art, not an exact science'. Gross anatomy experience is much more than learning the intricacies of the human body. The lessons learnt from the first day of unveiling the donor body who was once living like any of us, maintaining the lab etiquettes in handling the body from examining, lifting, turning and wrapping the body, working in small groups dissecting and discussing with fellow comraderies, the excitement in navigating through the fascia and locating the structures and finding anomalies teaches valuable lessons of care, compassion, communication, team building and cues about the unknown. This journey will be reiterated throughout a medical student's transition to a physician.

In conclusion, the COVID-19 pandemic has given new insight into teaching anatomy for medical students. The changes made during the pandemic may be temporary, however, the insights gained will definitely serve to refurbish the traditional tenets of teaching and assessment. Most advanced and sophisticated software cannot impart the essential traits and virtues of a physician learnt throughout a medical student's journey. The way to go ahead may be to use the online learning experiences alongside gross anatomy laboratory teaching to enhance learning.

\section{REFERENCES}

John Hopkins University and Medicine. Coronavirus Resource Center. From https://coronavirus.jhu. edu/map.html. [20 December 2020].

Onigbinde, O., Ajagbe, A., Oyeniran, O.I., Chia, T. 2020. Post-Covid-19 Pandemic: Standard Operating Procedures for Gross Anatomy Laboratory In The New Normal. Morphologie S1296-0115(20)30093-X.

World Health Organization WHO. Infection prevention and control for the safe management of a dead body in the context of COVID-19: interim guidance. 24 March 2020. From https://apps.who.int/iris/bitstream/ handle/10665/331538/WHO-COVID-19- IPC_ DBMgmt-2020.1-eng.pdf. [24 March 2020] 